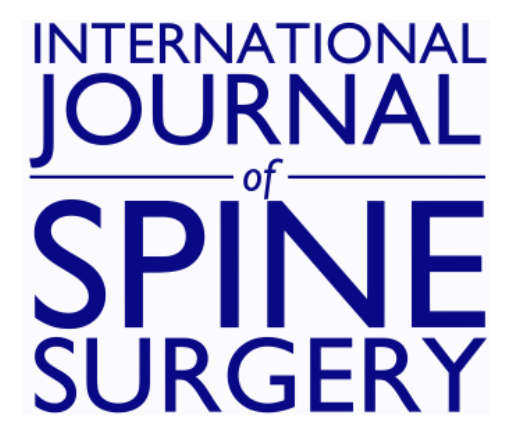

\title{
A Comparison of Three Different Methods of Fixation in the Management of Thoracolumbar Fractures
}

Pavlos Panteliadis, Omar Musbahi, Senthil Muthian, Shivam Goyal, Alexander Sheriff Montgomery and Arun Ranganathan

Int J Spine Surg 2017, 11 (5)

doi: https://doi.org/10.14444/4032

http://ijssurgery.com/content/11/5/32

This information is current as of April 26, 2023.

Email Alerts Receive free email-alerts when new articles cite this article. Sign up at:

http://ijssurgery.com/alerts

The International Journal of Sowine Surgerhhttp://ijssurgery.com/ by guest on April 26, 2 2397 Waterbury Circle, Suite 1,

Aurora, IL 60504, Phone: +1-630-375-1432

(C) 2017 ISASS. All Rights Reserved. 


\section{A Comparison of Three Different Methods of Fixation in the Management of Thoracolumbar Fractures}

Pavlos Panteliadis, MD ${ }^{1}$ Omar Musbahi, BEng(Hons), MBBS, 2,3 Senthil Muthian, MRCS, ${ }^{4}$ Shivam Goyal, ${ }^{3}$ Alexander Sheriff Montgomery, FRCS, ${ }^{4}$ Arun Ranganathan, FRCS 4

${ }^{1}$ Department of Trauma and Orthopedics, Guy's Hospital, Guy's and St Thomas NHS Trust, London, England, 2Oxford University Clinical Academic Graduate School, Oxford University, Oxford, England, '3Bart's and The London School of Medicine and Dentistry, Queen Mary University of London, London, England, ${ }^{4}$ Spinal Department, Royal London Hospital, Whitechapel Rd, London, England

\section{Abstract}

Introduction

Management of thoracolumbar fractures remains controversial in the literature. The primary aims of this study were to assess different levels of fixation with respect to radiological outcomes in terms of fracture reduction and future loss of correction.

\section{Methods}

This is a single center, retrospective study. Fifty-five patients presenting with thoracolumbar fractures between January 2012 and December 2015 were analyzed in the study. The levels of fixation were divided in 3 groups, 1 vertebra above and 1 below the fracture (1/1), 2 above and 2 below (2/2), and 2 above and 1 below (2/1).

\section{Results}

The most common mechanism was high fall injury and the most common vertebra L1. Burst fractures were the ones with the highest incidence. The $2 / 2$ fixation achieved the best reduction of the fracture but with no statistical significance. The correction is maintained better by the $2 / 2$ fixation but there is no statistical difference compared to the other fixations. Insertion of screws at the fracture level did not improve outcomes.

\section{Conclusion}

The data of this study identified a trend towards better radiological outcomes for fracture reduction and maintenance of the correction in the $2 / 2$ fixations. However these results are not statistically significant. Future multicenter prospective clinical trials are needed in order to agree on the ideal management and method of fixation for thoracolumbar fractures.

LUMBAR SPINE

KEYWORDS: THORACOLUMBAR, SPINE, FRACTURES, FIXATION, SURGERY

VOLUME 11 ISSUE 5 DOI: 10.14444/4032

PAGES $263-270$

\section{Introduction}

The majority of vertebral fractures in the axial skeleton occur in the thoracolumbar spine. ${ }^{1}$ The thoracolumbar area is the transition of the rigid thoracic spine into the mobile lumbar spine and it is considered biomechanically the weakest part of the spine. This characteristic makes it vulnerable to increased stresses and injuries. ${ }^{1-3}$ Thoracolumbar injuries are usually the result of high energy trauma like motor vehicle accidents or falls from a height. ${ }^{1}$

Numerous thoracolumbar fracture classifications have been proposed that aim to help in diagnosis, guide treatment and help with communication. Amongst the most significant are the ones proposed by Dennis, Magerl, the Thoracolumbar Injury Classification System (TLICS) by Vaccaro and the AOSpine Thoracolumbar spine injury classification system by Vaccaro. ${ }^{4-7}$ The Denis classification system introduced a modern concept on spinal stability, the 3-column theory. CT and MRI scans later revealed a more complex stability mechanism and rendered the Denis Classification as an incomplete model however it is still thought to have some use in modern practice. The latest AOSpine Thoracolumbar spine injury classification system (Table 1) combines the strengths of the Magerl and TLICS in terms of mor- 
phologic classification. ${ }^{1,8}$

Management of thoracolumbar fractures remains controversial. The goals of treatment in thoracolumbar fractures is to achieve a painless, stable spine with normal neurology and maximum mobility, which is well balanced in the sagittal plane in order to have an ergonomic stance. . $^{1,29,10}$

The treatment of thoracolumbar fractures can be either conservative or surgical. In the majority of cases the outcomes of conservative management satisfy patient and doctors expectations. Surgical management in thoracolumbar fractures can be warranted in unstable fractures and those associated with neurologic deficit. In the surgical group the approaches that can be used are anterior surgery, posterior surgery and combination of anterior and posterior surgery. There is extensive literature on different surgical techniques for reduction and stabilization of the fractures but no consensus on the ideal treatment. Finally the expertise and preference of the surgeon is an important factor on the decision of which technique to use. ${ }^{1,10,11}$ Indications for surgical interventions are not clear and are mostly influenced by surgeons preference however in our institution general indications for surgery as per $\mathrm{AO}$ classification

\begin{tabular}{|c|c|}
\hline $\begin{array}{l}\text { Type } \\
\text { A }\end{array}$ & COMPRESSION FRACTURE \\
\hline A 0 & $\begin{array}{l}\text { No fracture of the vertebral body - Fracture of the spinous or trans- } \\
\text { verse process }\end{array}$ \\
\hline A1 & $\begin{array}{l}\text { Wedge compression fracture with single endplate involvement and no } \\
\text { posterior wall involvement }\end{array}$ \\
\hline A2 & Split or pincer type fracture \\
\hline A3 & Incomplete burst fracture: Single endplate fracture \\
\hline A4 & Complete burst fracture \\
\hline $\begin{array}{l}\text { Type } \\
\text { B }\end{array}$ & TENSION BAND INJURIES \\
\hline B1 & Monosegmental bony posterior band injury \\
\hline B2 & Posterior tension band disruption: Bony and/or ligamentous \\
\hline B3 & Hyperextension injury \\
\hline $\begin{array}{l}\text { Type } \\
\text { C }\end{array}$ & DISPLACEMENT/ TRANSLATIONAL INJURIES \\
\hline $\mathrm{C}$ & Displacement beyond physiological range \\
\hline
\end{tabular}

are:

- A1, A2 fractures when the compression is more than $50 \%$ and depending on the state of the posterior ligamentous complex

- A3, A4 fractures depending on the fracture configuration

- $B$ and $C$ fractures are unstable hence operative management is mainstay

In posterior spinal fixations transpedicular screws are inserted above and below the fractured level to achieve reduction and control segmental kyphosis. The number of fixation levels above and below the fracture is still contentious in the literature..$^{12}$ The results in terms of fracture reduction and long term control of the kyphosis are debatable. ${ }^{13,14}$

General surgical approach either minimally invasive surgery (MIS) or an open approach was down to surgeons approach. However in our institution we favor open approach if there is neurological deficit or neural element compression.

The aim of this study is to determine if there is any difference in radiological outcomes between different levels of fixation for thoracolumbar fractures.

The secondary aims that were investigated include:

1. Mechanism of injury (MOI) and its association with neurological deficit.

2. MOI and its association with the type of fracture. 3. To assess if insertion of screws at the fracture site affects fracture reduction and maintenance of correction.

4. Metal work complications.

\section{Methodology}

\section{Study Design}

This study was designed as a single center retrospective study. The purpose was to evaluate the levels of fixation and techniques used in the management of thoracolumbar fractures with respect to radiological outcomes. Fracture reduction, was assessed by comparing the Cobb angle at the fracture level preoperatively and immediately postoperatively. The loss of 
correction was assessed by comparing the Cobb angle immediately postoperatively, 6 and 12 months after. The Cobb angle was measured from the superior endplate of the vertebrae above the fracture level to the inferior endplate of the vertebrae below the fracture level by one orthopaedic surgeon from a mixture of both x-rays and CT scans, pre and post operatively in supine and standing positions respectively (Figure $1)$.

Inclusion criteria included: skeletally mature patients with no age restriction, no gender restriction, presence of a thoracolumbar fracture (T10-L2), surgical management and follow up of at least 6 months.

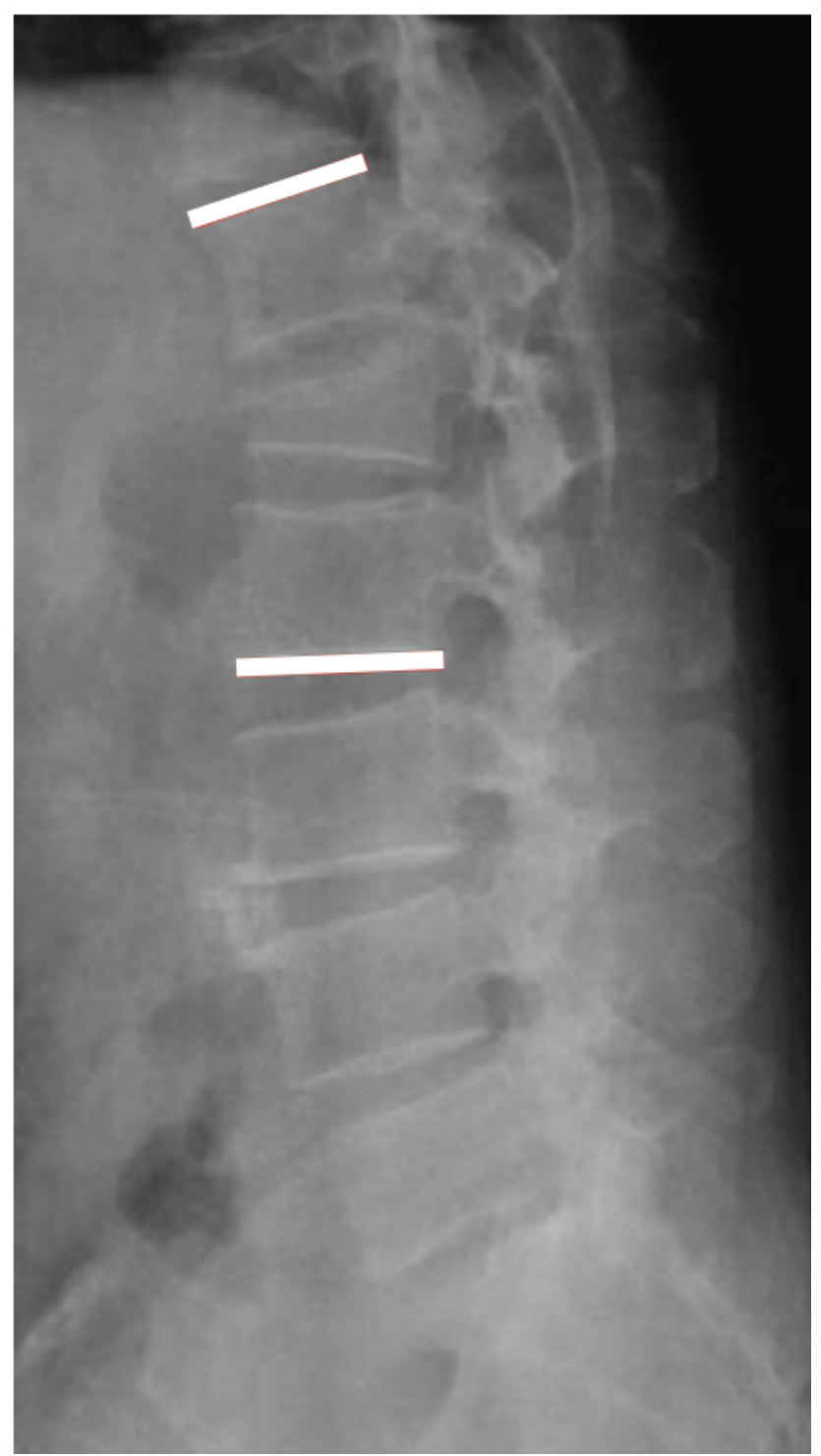

Fig. 1. Lateral radiograph demonstrating measurement of Cobb angle and segmental kyphosis.
All spinal trauma patients admitted to a Major Trauma Centre between January 2012 and December 2015 were identified retrospectively using the ICD-10 Diagnosis codes from the Business Analyst Unit of the trust. The patient list was categorized by the ICD-10 codes into Cervical, Thoracic and Lumbar fractures. A picture archiving and communication system (PACS) was used to identify thoracolumbar fractures. The cohort was subsequently divided into 3 groups according to the levels of posterior fixation. These were fixations extending 1 vertebra above and 1 vertebra below the fracture (1/1), fixations extending 2 vertebrae above and 2 vertebrae below the fracture $(2 / 2)$, and fixations extending 2 vertebrae above and 1 below the fracture (2/1). 64\% of patients were treated with an MIS and 36\% were open approaches.

Data extracted were patient demographics (age, gender), MOI, neurologic status, fracture and fixation levels, length of hospitalization and metal work complications. The cases that had insertion of a screw at the fracture level were recorded. Radiographs were processed with PACS and used to measure the fracture reduction and loss of correction. Fractures were classified according to the AOSpine Thoracolumbar spine injury classification system (A.1). All data were entered into a Microsoft Excel spreadsheet.

\section{Statistical Analysis}

The analysis of the data was made with the statistical software for data analysis SPSS Statistics version 22.0. The variables normal distribution was checked and confirmed by the Shapiro-Wilk test. Descriptive statistics were used to illustrate the measures on every metric while inferential statistics were used to identify any relationship between the different variables and answer on the research questions. The chisquare test was used to assess the association of the MOI with the type of fracture and the neurologic deficit. The ANOVA test was used to compare the posterior fixation methods in the group of $2 / 2 \mathrm{vs} .2 / 1$ vs. $1 / 1$. The independent T-Test was used to compare the levels of fixation in pairs of 2 , as well as to compare the Open vs. MIS technique and to investigate if the insertion of screw at the fracture level affects the radiological outcomes. 
For all statistical tests, the level of significance was set at $\mathrm{p}<0.05$.

\section{Results}

1204 patients were identified with fractures of the thoracic and lumbar spine. From which 448 patients were identified with thoracolumbar fracture. Of these 448,112 patients underwent surgical management. 55 patients of the 112 fulfilled the inclusion criteria. The mean age of the patients was 40 (range: 19-74). There were 38 male $(69.1 \%)$ and 17 female (30.9\%) patients. The MOI were categorized (Figure 2) and the most common was high fall injury $(\mathrm{n}=36,65.5 \%)$ followed by road traffic accidents (RTA) $(\mathrm{n}=9$, $16.4 \%)$.

Among the fractured vertebrae L1 $(\mathrm{n}=28,50.1 \%)$ had the highest frequency followed by $\mathrm{T} 12(\mathrm{n}=14,25.5 \%)$, L2 $(n=7,12.7 \%)$, T11 $(n=4,7.3 \%)$ and T10 $(n=2,3.6 \%)$. The fractures were classified (Table 2 ) according to the "AOSpine Thoracolumbar Spine Injury Classification." 7 The most common type was burst fractures comprising $78.2 \%$ of all injuries (47.3\% were type A3, $30.9 \%$ type A4). Seven patients (12.7\%) had neurological deficit.

The MOI and its association with neurological deficit and the type of fracture were investigated. It was found that there is no relationship with either neurologic deficit (p: 0.603) or type of fracture (p: 0.955). There was 1 metal work failure at the fixation level of $1 / 1$.

55 patients were included in the 3 groups of fixation levels $(1 / 1 \mathrm{n}=30,2 / 2 \mathrm{n}=9,2 / 1 \mathrm{n}=16)$. All surgeries

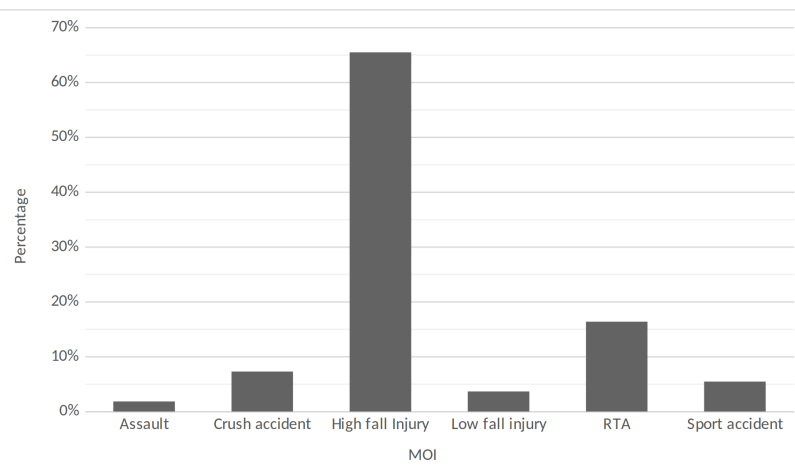

Fig. 2. Mechanism of injury (MOI) of patients with thoracolumbar fractures our study. were performed by two surgeons (AM and AR).

Reduction of the fracture (Table 3) was assessed by comparing the preoperative and postoperative segmental kyphosis. The results showed that the best reduction was achieved by the $2 / 2$ fixation (mean correction $11.7^{\circ}$ ) and the worst by the $1 / 1$ fixation (mean correction $6^{\circ}$ ) but there was no statistical significance when we compared $2 / 2$ vs. $2 / 1$ vs. $1 / 1$ together (p: 0.119 ). However comparison of $2 / 2$ to $1 / 1$ showed that the $2 / 2$ fixation had a significant better result (p: 0.016) on reduction of the fracture. Looking at the Open (mean correction $8.5^{\circ}$ ) Vs MIS (mean correction $6.5^{\circ}$ ) technique on fracture reduction there was no significant difference between the two techniques (p:0.330) but the open technique achieved a better reduction in our study group.

The loss of correction (Table 3) was significantly greater in patients who underwent fixation with $2 / 1$ (mean: $2.6^{\circ}$ ) and $1 / 1$ (mean: $6.4^{\circ}$ ) constructs compared with $2 / 2$ (mean: $0.1^{\circ}$ ) construct at six months (p:0.034). At 12 months the loss of correction was not statistically significant (p: 0.793 ) but the $2 / 2$ construct continues to have the smallest loss of correc-

Table 2. Fracture Classification According to AOSpine Thoracolumbar Spine
Injury.
\begin{tabular}{|l|r|r|}
\hline Type & Frequency & Percentage \\
\hline A1 & 4 & 7.2 \\
\hline A2 & 26 & 7.2 \\
\hline A3 & 17 & 47.3 \\
\hline A4 & 2 & 30.9 \\
\hline B1 & 1 & 3.6 \\
\hline B2 & 1 & 1.8 \\
\hline C & 55 & 1.8 \\
\hline Total & & 100.0 \\
\hline
\end{tabular}

Table 3. Radiological Outcomes of Different Levels of Fixation.

\begin{tabular}{|l|r|r|r|}
\hline \multirow{2}{*}{ Levels of fixation } & Fracture Reduction & \multicolumn{2}{|c|}{ Loss of correction } \\
\cline { 3 - 4 } & $11.7^{\circ}$ & $0.1^{\circ}$ & $3.8^{\circ}$ \\
\hline $2 / 2$ & $7^{\circ}$ & $2.6^{\circ}$ & $8^{\circ}$ \\
\hline $2 / 1$ & $6^{\circ}$ & $6.4^{\circ}$ & $6^{\circ}$ \\
\hline $1 / 1$ & & 12 months \\
\hline
\end{tabular}


tion with a mean of $3.8^{\circ}$ compared to $2 / 1$ (mean: $8^{\circ}$ ) and $1 / 1$ (mean: $6^{\circ}$ ).

Comparing the results concerning the loss of correction between the open and MIS technique; the open technique has less loss of correction compared to MIS at both 6 months (Open: $2.1^{\circ}$, MIS: $5.5^{\circ}$ ) and 12 months (Open: $3.4^{\circ}$, MIS: $7.9^{\circ}$ ) but there is no statistical difference for both 6 months (p:0.095) and 12 months (0.216).

In 31 cases, screws were inserted at the fracture site. The results showed that the insertion of screws at the fracture site did not have a statistical significant effect on the fracture reduction (p: 0.086) or on the loss of reduction at 6 months (p: 0.073 ) or 12 months (p: 0.450). Finally the open and MIS techniques were compared to assess whether there was a difference in patients' length of stay. The mean for MIS was 23 days and for open 29 days. There was no statistical significant difference (p: 0.383 ) between the 2 groups.

\section{Discussion}

This study included 55 patients. The most common mechanism of injury was high fall injury while the vertebrae most involved were L1 followed by T12. Burst fractures were the type of injury with the highest frequency. 9 fractures were associated with neurologic deficit.

Comparing the radiological outcomes (Table 3) associated with the levels of fixation, the results show that the best reduction was achieved by the $2 / 2$ and the worst by the $1 / 1$ construct but there was no statistical significance between the 3 fixations. In terms of loss of correction the $2 / 2$ construct maintains correction better than the $1 / 1$ and $2 / 1$. At 6 months this difference is significant but at 12 months there is no statistical significance.

As per the results there was no correlation between the mechanism of injury with neurologic deficit or the type of fracture. Insertion of screws at the fracture level did not improve the reduction or the loss of correction at 6 and 12 months.
Looking at the results in relation to the hypothesis and the primary aims of the study, there is no statistical significant difference between the different levels of fixation. However, one can observe that $2 / 2$ fixation results in better reduction of the fracture and maintenance of the correction.

\section{Review of the Literature}

The management of thoracolumbar fractures remains controversial. Posterior spinal instrumentation is the most frequent method of fixation due to the low morbidity and comorbidity. ${ }^{15}$ Our results show that overall posterior fixation results in loss of correction over time. When there is no anterior support the injured intervertebral disc and the fractured vertebrae may collapse further and result in loss of the reduction by $7^{\circ}$ to $9^{\circ} \cdot{ }^{16,17}$ Curfs et al. investigated the relationship of posttraumatic kyphosis with the type of fracture and the location. They found that A3 fractures and T12-L1 location were at increased risk of developing kyphosis. In this series the most common fracture was type $\mathrm{A} 3$ and the most common location $\mathrm{L} 1$ and $\mathrm{T} 12 .{ }^{18}$

Although there was no statistical significance between the 3 different levels of fixation, the superiority of the $2 / 2$ construct on fracture reduction and maintenance of correction can be because of the extra stiffness and strength it provides compared to the other constructs. ${ }^{12}$ Tezeren et al. compared $2 / 2$ vs. $1 /$ 1 fixations and found similar results; $2 / 2$ fixations being superior at both reducing and controlling the fracture. The same conclusion was made by Waqar et al. in their series looking at long vs. short fixations. ${ }^{12}$ On the contrary Sapkas et al. found that both long and short fixation reduce the fracture equally well but long fixation control it better in the long term. ${ }^{19}$ Park et al. compared fixations of $1 / 1$ vs. $2 / 1$ and found no differences in fracture reduction and maintenance of the correction. They suggested that $1 / 1$ fixations can be used successfully. ${ }^{20}$ Similarly, Aono et al. studied $1 / 1$ constructs and concluded that it can provide satisfactory reduction and maintenance of the correction. The neurological deficit they reported was $52 \%$ which was significantly higher that this study. ${ }^{17}$ 
$\mathrm{Li}$ et al. investigated if insertion of screws at the fracture level would improve fracture reduction and maintenance of the correction. They reported that they achieved better reduction and less loss of the correction. ${ }^{21}$ Okten et al. reported similar results in their series; they compared fixations that included one vertebra above and one below the fracture level. They found that a screw at the fracture level resulted in a greater fracture reduction but they did not report long term results. ${ }^{15}$ These results are different than the data of this study. Both Waqar and Sapkas report higher incidence of metal work failure compared to this series. ${ }^{12,19}$

A systematic review by Phan et al. ${ }^{22}$ concluded that there was a statistical difference between MIS and Open approach in length of hospital stay. This statistical significance was not observed in our cohort of patients, quite possibly as many of our patients were polytrauma patients.

The literature is highly controversial, with no clear guidance on the ideal treatment.

\section{Limitations}

Limitations of this study include the nonrandomized and retrospective design. The sample size was also small especially considering that there was comparison of three different groups. Furthermore a limitation that was observed in the literature and this study is that radiological evaluation of the fracture reduction and the maintenance of correction depends on the measurement of the Cobb angle. Whilst inter-observer and intra-observer variability of Cobbs angle measurement is high, we acknowledge that calculating a kappa coefficient would have lent greater validity to our measurements. Due to the fact that in this study as other studies in the literature there is no pre fracture data, the normal pre fracture values are not known. As a result the amount of reduction that will be sufficient as well as the loss of correction that will be abnormal are not known. This is especially important for surgical fixations, if we take into consideration Roussouly's theory on the functional segmentation of the spine where the inflexion point, which is defined as the point where the thoracic kyphosis turns into lumbar lordosis, does not always correspond to T12-L1. ${ }^{23}$

\section{Conclusion}

The current literature does not specify a gold standard for the treatment of thoracolumbar fractures. The results of this study show better fracture reduction and maintenance of the correction in the $2 / 2$ fixations compared to $2 / 1$ and $1 / 1$. However these results are not statistically significant in the long term.

Although the results of this study and the literature do not show any statistical significance towards a specific fixation or technique; the authors' view is that a trend can be observed in favor of longer instrumentations. Future multicenter prospective clinical trials are needed in order to agree on the ideal management and method of fixation for thoracolumbar fractures.

\section{Ethics Statement}

Ethical approval was not needed for this study. The study was approved by the Spinal Department, Royal London Hospital as a service evaluation project.

\section{References}

1. Wood KB, Li W, Lebl DR, Lebl DS, Ploumis A. Management of thoracolumbar spine fractures. Spine J. 2014;14(1):145-164. doi:10.1016/

j.spinee.2012.10.041.

2. Cahueque M, Cobar A, Zuñiga C, Caldera G. Management of burst fractures in the thoracolumbar spine. J Orthop. 2016;13(4):278-281. doi:10.1016/ j.jor.2016.06.007.

3. Holmes JF, Miller PQ, Panacek EA, Lin S, Horne NS, Mower WR. Epidemiology of Thoracolumbar Spine Injury in Blunt Trauma. Acad Emerg Med. 2001;8(9):866-872. doi:10.1111/ j.1553-2712.2001.tb01146.x.

4. Denis F. The three column spine and its significance in the classification of acute thoracolumbar spinal injuries. Spine (Philadelphia, Pa 1976).

1983;8(8):817-831. doi:10.1007/

978-1-4471-5451-8 71. 
5. Magerl F, Aebi M, Gertzbein SD, Harms J, Nazarian S. A comprehensive classification of thoracic and lumbar injuries. Eur Spine J. 1994;3(4):184-201. doi:10.1007/BF02221591.

6. Vaccaro AR, Lehman RA, Hurlbert RJ, et al. A New Classification of Thoracolumbar Injuries. Spine (Phila Pa 1976). 2005;30(20):2325-2333. doi:10.1097/ 01.brs.0000182986.43345.cb.

7. Vaccaro AR, Oner C, Kepler CK, et al. AOSpine Thoracolumbar Spine Injury Classification System. Spine (Phila Pa 1976). 2013;38(23):2028-2037. doi:10.1097/BRS.0b013e3182a8a381.

8. Kepler CK, Vaccaro AR, Schroeder GD, et al. The Thoracolumbar AOSpine Injury Score. Glob Spine J. 2015;29.09.2015(EFirst). doi:10.1055/ s-0035-1563610.

9. Jindal N, Sankhala SS, Bachhal V. The role of fusion in the management of burst fractures of the thoracolumbar spine treated by short segment pedicle screw fixation: a prospective randomised trial. J Bone Joint Surg Br. 2012;94(8):1101-1106. doi:10.1302/ 0301-620X.94B8.28311.

10. Verlaan JJ, Diekerhof CH, Buskens E, et al. Surgical treatment of traumatic fractures of the thoracic and lumbar spine: a systematic review of the literature on techniques, complications, and outcome. Spine (Phila Pa 1976). 2004;29(7):803-814. doi:10.1097/01.BRS.0000116990.31984.A9.

11. Norton RP, Milne EL, Kaimrajh DN, Eismont FJ, Latta LL, Williams SK. Biomechanical analysis of four- Versus six-screw constructs for short-segment pedicle screw and rod instrumentation of unstable thoracolumbar fractures. Spine $J$. 2014;14(8):1734-1739. doi:10.1016/ j.spinee.2014.01.035.

12. Waqar M, Van-Popta D, Barone DG, Bhojak M, Pillay R, Sarsam Z. Short versus long-segment posterior fixation in the treatment of thoracolumbar junction fractures: a comparison of outcomes. $\mathrm{Br} \mathrm{J} \mathrm{Neu}$ rosurg. 2016;8697( July):1-4. doi:10.1080/ 02688697.2016.1206185.
13. Mcanany SJ, Anderson PA, Overley SC, Kim JS, Baird EO, Qureshi SA. Open Versus Minimally Invasive Fixation. Glob SPINE J. 2016:186-194.

14. Fitschen-Oestern S, Scheuerlein F, Weuster M, et al. Reduction and retention of thoracolumbar fractures by minimally invasive stabilisation versus open posterior instrumentation. Injury. 2015;46:S63-S70. doi:10.1016/S0020-1383(15)30020-6.

15. Ali İhsan Ökten, Yurdal Gezercan, Kerem Mazhar Özsoy, Tuncay Ateş, Güner Menekşe, Ali Aslan, Eralp Çetinalp AG. Results of treatment of unstable thoracolumbar burst fractures using pedicle instrumentation with and without fracture-level screws. Acta Neurochir (Wien). 2015;157(5):831-836. doi:10.1007/s00701-015-2383-y.

16. Tezeren G, Kuru I. Posterior fixation of thoracolumbar burst fracture: short-segment pedicle fixation versus long-segment instrumentation. J Spinal Disord Tech. 2005;18(6):485-488. doi:10.1097/ 01.bsd.0000149874.61397.38.

17. Aono H, Tobimatsu H, Ariga K, et al. Surgical outcomes of temporary short-segment instrumentation without augmentation for thoracolumbar burst fractures. Injury. 2016;47(6):1337-1344. doi:10.1016/ j.injury.2016.03.003.

18. Curfs I, Grimm B, Linde $M$ van der, Willems $P$, Hemert W van. Radiological Prediction of Posttraumatic Kyphosis After Thoracolumbar Fracture. Open Orthop J. 2016;10(1):135-142. doi:10.2174/ 1874325001610010135 .

19. Sapkas G, Kateros K, Papadakis SA, Brilakis E, Macheras G, Katonis P. Treatment of unstable thoracolumbar burst fractures by indirect reduction and posterior stabilization: short-segment versus longsegment stabilization. Open Orthop J. 2010;4:7-13. doi:10.2174/1874325001004010007.

20. Park S-R, Na H-Y, Kim J-M, Eun D-C, Son E-Y More than 5-Year Follow-up Results of Two-Level and Three-Level Posterior Fixations of Thoracolumbar Burst Fractures with Load-Sharing Scores of Seven and Eight Points. Clin Orthop Surg. 
21. Li K, Li Z, Ren X, et al. Effect of the percutaneous pedicle screw fixation at the fractured vertebra on the treatment of thoracolumbar fractures. Int Orthop. 2016;40(6):1103-1110. doi:10.1007/ s00264-016-3156-9.

22. K. P, P.J. R, R.J. M. Percutaneous versus open pedicle screw fixation for treatment of thoracolumbar fractures: Systematic review and meta-analysis of comparative studies. Clin Neurol Neurosurg.

2015;135:85-92.

23. Roussouly P, Pinheiro-Franco JL. Sagittal parameters of the spine: biomechanical approach. European Spine Journal. 2011:1-8.

\section{Disclosures \& COI}

The authors report no relevant financial disclosures or conflicts of interest. This research did not receive any specific grant from funding agencies in the public, commercial, or not-for-profit sectors.

\section{Corresponding Author}

Pavlos Panteliadis MD, Guy's Hospital, Guy's and St Thomas NHS Foundation Trust, London, SE1 9RT.panteliadispavlos@yahoo.com

Published 5 December 2017.

This manuscript is generously published free of charge by ISASS, the International Society for the Advancement of Spine Surgery. Copyright @ 2017 ISASS. To see more or order reprints or permissions, see http://ijssurgery.com. 